\title{
TINJAUAN KERAJINAN BERBAHAN SABUT KELAPA DI SENTRA CREABRUSH DESA MULYOREJO KECAMATAN SUNGGAL DELI SERDANG
}

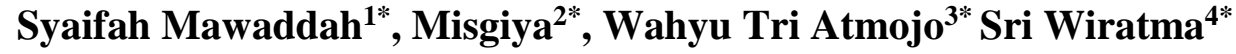 \\ Program Studi Pendidikan Seni Rupa Jurusan Seni Rupa Fakultas Bahasa dan Seni \\ Universitas Negeri Medan \\ Jl. Willem Iskandar Pasar V Medan Estate, Kec, Percut Sei Tuan, Kab. Deli Serdang, Kode Pos 20371 \\ Sumatera Utara. Indonesia \\ Email: syaifahmawaddah11a1@gmail.com
}

\begin{abstract}
Abstrak
Penelitian ini bertujuan untuk meninjau lebih jauh tentang jumlah bentuk yang dihasilkan, dan bagaimana perkembangan produk pada kerajinan berbahan sabut kelapa di Sentra Creabrush Desa Mulyorejo Kecamatan Sunggal Deli Serdang. Metode penelitian yang digunakan yaitu metode penelitian Deskriptif Kualitatif. Populasi yang terdapat dalam penelitian ini sebanyak 5 karya kerajinan sabut kelapa. Sampel yang digunakan dalam penelitian ini terdiri dari karya kerajinan sabut kelapa dengan menggunakan teknik Purposive Sampling yaitu teknik penentuan sampel dengan pertimbangan tertentu. Guna memperoleh data mengenai tinjauan terhadap kerajinan sabut kelapa di Sentra Creabrush Desa Mulyorejo Kecamatan Sunggal Deli Serdang. Setelah dilakukan pengumpulan data memalui instrumen penelitian observasi, wawancara dan dokumentasi, maka hasil penelitian menunjukkan bahwa proses pembuatan setiap kerajinan sabut kelapa pada Creabrush memiliki proses pembuatan yang berbeda-beda tergantung dari jenis kerajinannya, dan bahan dasar sabut kelapa yang utuh atau diolah dulu menjadi lembaran atau coco sheet. Bentuk karya seni kerajinan sabut kelapa yang dibedakan berdasarkan fungsinya yaitu homedecor dan fashioncraft, dan sebagian karya seni kerajinan sabut kelapa di sentra Creabrush seperti lukisan, kaligrafi, sepatu, sandal dan tas mengalami perkembangan dalam peroses pembuatan dan hasil karyanya dari waktu ke waktu.
\end{abstract}

Kata Kunci: tinjauan, kerajinan, sabut kelapa.

\begin{abstract}
This aims of this study are for reviewing the shapesof produced, and how the outgrowth in the coconut coir craft produc at the Creabrush Center at Desa Village, Kecamatan Sunggal Deli Serdang. The method of the study is descriptive qualitative research method. The populations in this study contained by 5 coconut coir crafts. The sample of this study consisted of coconut coir craft by using the Purposive Sampling technique, which is a sample determination technique with certain considerations. For colleting the data of this study at coconut coir handicrafts at the Creabrush Center at Desa Mulyorejo, Kecamatan Sunggal Deli Serdang. After the process collecting the data through observation research instruments, interviews and documentation, the results of this study show that the process for making the coconut husk craft in Creabrush has a different manufacturing process depended by the type of craft itself, and the basic material of coconut coir itsel finclude processing the material first or no. The product of coconut coir craft divided by aech functions, which are homedecor and fashioncraft, and some of coconut coir crafts whose works in the Creabrush centers such as paintings, calligraphy, shoes, slippers and bags has an increase in the process of making and also the products.
\end{abstract}

Keywords: enhancement, crafts, coconut coir.

\section{PENDAHULUAN}

Profil Kabupaten Deli Serdang dalam Ginting (2017 : 12) Kabupaten Deli Serdang terdiri dari dataran pantai, dataran rendah dan dataran tinggi pegunungan. Kelapa adalah tanaman tropis yang dapat tumbuh mulai dari pinggir pantai hingga ketinggian 1000 meter di atas permukaan laut, dengan demikian tanaman kelapa dapat tumbuh subur di daerah Kabupaten Deli Serdang.

Sebagai salah satu sentral kerajinan di Sumatera Utara. Potensi daerah yang cukup diunggulkan di Kabupaten Deli Serdang yaitu Produk UMKM yang berada dibidang kerajinan tangan (handy craft), souvenir dan aksesoris. Di antaranya berupa kerajin 
berbahan sabut kelapa, keramik, gerabah, batik, kain songket, kerajinan berbahan lidi, rajut, dan lain sebagainya.

Creabrush merupakan nama merek disalah satu usaha kerajinan yang bergerak dalam pembuatan bendabenda souvenir di Kabupaten Deli Serdang milik pengrajin Febri Yunarta. Berlokasi di jalan Medan Binjai KM 11,2 Desa Mulyorejo Kecamatan Sunggal Kabupaten Deli Serdang.

Berdasarkan hasil observasi awal yang dilakukan oleh peneliti melalui wawancara dengan pengrajin Creabrush mengatakan bahwa, melimpahnya limbah sabut kelapa yang tidak terpakai pengrajin mengembangkan ide kreatifnya dengan memanfaatkan limbah sabut kelapa tersebut menjadi sebuah kerajinan yang memiliki nilai seni dan nilai guna. permintaan pasar terhadap kerajinan sabut kelapa sangat beragam. Salah satunya adalah pengrajin harus pandai menciptakan produk berbahan sabut kelapa dengan berbagai macam kreasi agar permintaan pasar tetap terpenuhi. Selain itu kerajinan sabut kelapa hanya diproduksi jika ada pesanan saja.

\section{KAJIAN TEORI}

\section{Pengertian Tinjauan}

Kamus Praktis Bahasa Indonesia (2010:536) "Tinjauan adalah berupa hasil meninjau, mencari sudut pandang, pendapat, menyelidiki, suatu hal". Kegiatan yang berkaitan dengan tinjauan dilakukan karena menyangkut aspek-aspek tatanan persoalan yang menjadi akar penelitian. Tinjauan adalah melihat secara langsung suatu objek yang akan diteliti kebenarannya.Maka yang ditinjau dalam penelitian ini adalah kerajinan berbahan sabut kelapa di sentra creabrush desa mulyorejo kecamatan Sunggal Deli Serdang.

\section{Pengertian Kerajinan}

Menurut Yudoseputro dalam Milyartini, dkk (2002:7) "Kerajinan tangan (handy craft) diartikan sebagai hasil kegiatan olah tangan manusia dengan memanfaatkan berbagai bahan dan peralatan yang dilakukan secara cermat tekun dan terampil guna menghasilkan benda praktis dan menarik dipandang mata". Menurut Prasetya (2016 : 158) "Kerajinan diartikan sebagai pekerjaan yang dilakukan dengan tangan dan membutuhkan keterampilan tertentu". Menurut Ranelis \& Washinton (2016 : 59) "Kerajinan adalah karya seni yang diciptakan untuk dilihat atau dipakai (dipergunakan), khususnya dalam situasisituasi umum".
Gorga : Jurnal Seni Rupa

Volume 09 Nomor 01 Januari-Juni 2020

p-ISSN: 2301-5942 | e-ISSN: 2580-2380

\section{Kelapa}

Tree of life atau pohon kehidupan. Itulah julukan untuk pohon kelapa. Hampir seluruh bagian pohon kelapa berguna bagi manusia, mulai dari akar, batang, daun, bunga, dan buah. Menurut Hartono (2013:3) "Kelapa adalah tanaman tropis yang dapat tumbuh mulai dari pantai hingga ketinggian 1.000 meter diatas permukaan laut. Tanaman kelapa tumbuh optimal pada $10^{\circ} \mathrm{LS}$ (Lintang Selatan) hingga $10^{\circ} \mathrm{LU}$ (Lintang Utara) dan masih tumbuh baik pada $15^{\circ} \mathrm{LS}$ dan $15^{\circ}$ LU”.

\section{1). Jenis Tanaman}

Hartono (2013:4) Kedudukan Kelapa dalam klasifikasi taksonomi tumbuhan adalah sebagai berikut:

$\begin{array}{ll}\text { Kingdom } & : \text { Plantae (tumbuh-tumbuhan) } \\ \text { Divisio } & \text { : Spermatophyta (tumbuhan berbiji) } \\ \text { Sub-Divisio } & \text { : Angiospermae (berbiji tertutup) } \\ \text { Kelas } & \text { :Monocotyldonae (biji berkeping } \\ \text { satu) } & \\ \text { Ordo } & : \text { Palmales } \\ \text { Familia } & : \text { Palmae } \\ \text { Genus } & : \text { Cocos } \\ \text { Spesies } & : \text { Cocos nucifera L. }\end{array}$

Jenis Kelapa dengan beragam Varietas yang bisa dibudidayakan antara lain: Hartono (2013:12) Kelapa Dalam, jenis kelapa dalam terdiri dari beberapa varietas : kelapa hijau (varietas viridis), kelapa merah (varietas rubescens), kelapa kelabu (varietas macroocorpu), dan kelapa manis (varietas sakarina). Kelapa dalam memiliki batang yang tinggi hingga mencapai 30 meter. Pembuahannya lambat, sekitar 7-8 tahun baru berbuah. Jumlah buah antara 6-12 buah pertandan dengan fase pembuahan 12 bulan sehingga dalam setahun dapat menghasilkan 90 buah perpohon. Umurnya bisa mencapai lebih dari 100 tahun dan memiliki kualitas kopra, minyak dan sabut yang bagus.

Hartono (2013:12) Kelapa Genjah, jenis kelapa genjah antara lain kelapa gading (varietas eburnean), kelapa raja (verietas regia), kelapa puyuh (varietas pumila), dan kelapa raja malabar (varietas pretiosa). Kelapa genjah memiliki pohon yang relatif lebih rendah. Batangnya kecil dan lurus tanpa bol. Jenis kelapa ini cepat berbunga, yaitu mulai umur 3-4 tahun. jumlah buah pertandan bisa mencapai 10-30 buah dengan fase pembuahan 11-12 bulan. Kualitas kopranya kurang bagus dan setelah 25 tahun, produksi buahnya mulai menurun. Kelapa genjah memiliki beberapa kelemahan seperti dipengaruhi fluktuasi iklim, ukuran 


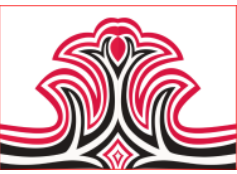

buah yang relatif kecil sehingga bila dijadikan kopra hanya menghasilkan 130 gram perbuah.

Hartono (2013:13) Kelapa hibrida, pada dekade 19701980 pemerintah mendorong pengembangan kelapa hibrida karena memiliki produktivitas yang tinggi. Kelapa hibrida mulai berbuah sekitar 3-4 tahun. produksi kopra bisa mencapai 6-7 ton per hektar per tahun pada umur 10 tahun. Daging buahnya tebal dan keras, kadar minyak relatif tinggi, dan habitus tanaman sedang. Produksi tandan buah bisa mencapai 12 dan setiap tandan bisa berisi 10-20 buah kelapa.

Hartono (2013:13) Kelapa kopyor, kelapa ini adalah kelapa abnormal yang terjadi secara genetik. Daging buah lunak, berbutir-butir, dan berkadar minyak rendah. Buah kelapa ini tidak dapat tumbuh menjadi benih karena kentos tidak berfungsi sebagai alat penghisap zat makanan dan susunan lembaganya sangat lunak sehingga tidak mampu menembus lapisan sabut kelapa untuk tumbuh.

\section{2). Anatomi Buah Kelapa}

Tabel. 1. Anatomi Buah Kelapa

\begin{tabular}{|c|c|}
\hline Bagian Buah Kelapa & Komposisi \\
\hline $\begin{array}{ll} & \text { Sabut : } \\
-\quad & \text { Kulit luar (eksokarpim) } \\
-\quad & \text { Sabut (mesokarpium) }\end{array}$ & $25-32 \%$ \\
\hline $\begin{array}{l}\text { Tempurung } \\
\text { (endokarpium) }\end{array}$ & $12-13,1 \%$ \\
\hline 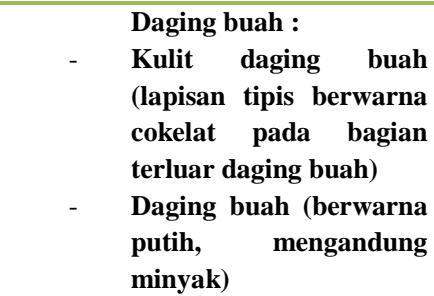 & $28-34,9 \%$ \\
\hline Air buah kelapa & $19,2-25 \%$ \\
\hline
\end{tabular}

Sumber : Hartono (2014:14)

\section{Sabut Kelapa}

Hartono (2013:19) "Sabut kelapa merupakan bagian yang cukup besar dari buah kelapa, yaitu $35 \%$ dari berat keseluruhan buah. Sabut kelapa terdiri dari serat dan gabus yang menghubungkan satu serat dengan serat lainnya. Serat adalah bagian yang berharga dari sabut. Setiap butir kelapa mengandung serat 525 gram (75\% dari sabut), dan gabus 175 gram (25\% dari sabut)". Hartono (2013:19) Sabut kelapa menghasilkan serat yang dapat diolah menjadi beragam produk yang bernilai ekonomi dan ekologis. Serat sabut kelapa dapat dibuat dalam bentuk lembaran yang dikenal dengan sebutan coco sheet. Serat sabut kelapa dapat diolah menjadi bahan baku industri karpet, jok, dardboard kendaraan, kasur, bantal dan hardboard. Sabut kelapa nilai tambahan
Gorga : Jurnal Seni Rupa

Volume 09 Nomor 01 Januari-Juni 2020

p-ISSN: 2301-5942 | e-ISSN: 2580-2380

ekonomi dengan sentuhan teknologi yang sederhana. Skala usahanya bisa dilakukan dari rumah tangga, usaha kecil, menengah, dan usaha besar.

\section{Teknik Pembuatan}

Menurut Nurhadiat (2004:75) "Teknik Pembuatan seni kriya yang diproses tergantung kepada karakter bahan. Bahan keras dibentuk dengan mengukir atau menempel. Bahan lunak dibentuk dengan membutsir atau mencetak dan lain-lain". Menurut Milasari dkk (2018:33) Dalam berkarya seni, proses pembuatannya disebut teknik.

\section{METODE PENELITIAN}

Metode yang digunakan dalam penelitian ini adalah deskriptif kualitatif. Teknik pengumpulan data yang digunakan observasi, wawancara dan dokumentasi. Instrumen peneltian yang digunkan yaitu buku catatan, kamera dan daftar pertanyaan. Teknik analisis data yang digunakan yaitu deskriptif kualitatif.

\section{HASIL DAN PEMBAHASAN \\ 1.Hasil}

1).Karya 1

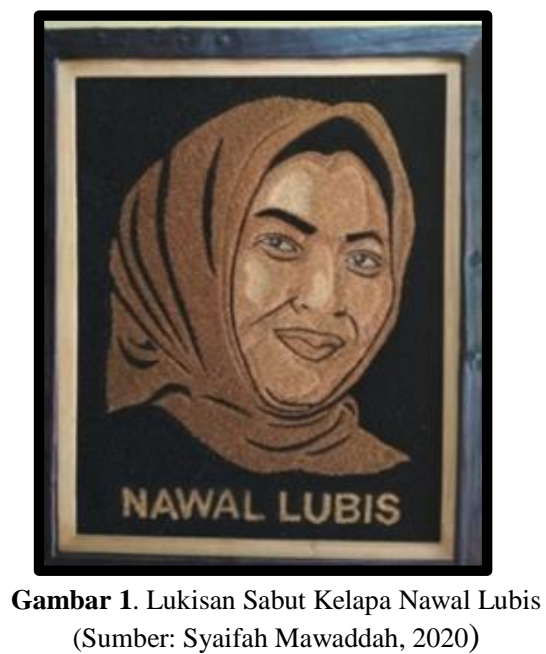

Tinjauan bentuk yang ditampilkan pada kerajinan sabut kelapa ini yaitu menampilkan bentuk lukisan sabut kelapa wajah perempuan dengan bahan sabut kelapa dan ijuk yang dipotong berukuran $\pm 1 \mathrm{~cm}$, pada lukisan ini sudah mengalami banyak kemajuan dalam penyusunannya karena sabut kelapa dan ijuk yang tersusun berdiri keseluruhannya. Lukisan ini berukuran panjang $70 \mathrm{~cm}$, dan lebar $50 \mathrm{~cm}$.

Proses pembuatan lukisan ini awalnya sabut kelapa dan ijuk dipotong berukuran $\pm 1 \mathrm{~cm}$, kanvas digambar membentuk pola objek yang diinginkan, setelah itu diolesi lem menggunakan kuas kecil untuk bagian yang akan ditaburi sabut kelapa, tabur sabut kelapa 


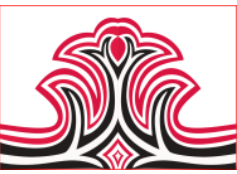

sesuai pola gambar (pada tahap ini terdapat proses pembuatan yang dirahasiakan oleh pengrajin) lalu dijemur di bawah sinar matahari hingga kering, setelah kering olesi lem dibagian yang akan ditaburi ijuk lalu jemur kembali, setelah bener-benar kering sebagai penyelesaian akhir, lukisan disemprotkan lem menggunakan gun spray agar sabut kelapa dan ijuk benar-benar melekat dengan kuat lalu dijemur kembali hingga kering. Pengerjaan lukisan sabut kelapa ini memakan waktu kurang lebih dua minggu lamanya tergantung tingkat kerumitan gambar dan waktu penjemuran.

Lukisan ini dapat dikatakan periode keempat dalam pembuatan lukisan sabut kelapa, untuk mendapatkan hasil karya seperti diatas membutuhkan waktu yang cukup lama dan melalui proses yang panjang. Lukisan ini terkesan sederhana, namun karena kreativitas sang pengrajin lukisan sabut kelapa ini terlihat unik dan menarik sehingga memiliki nilai jual yang tinggi.

\section{2).Karya 2}

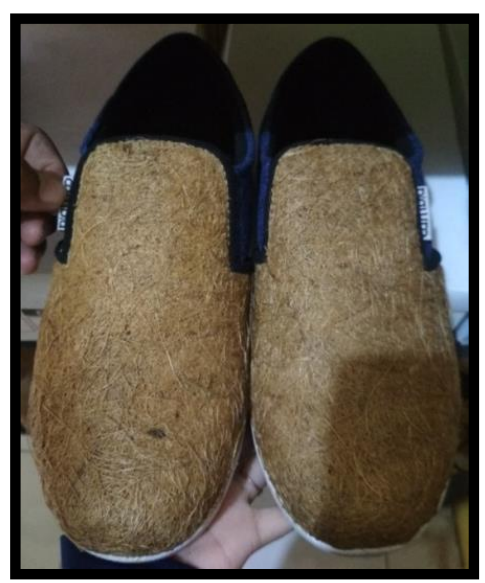

Gambar 2. Sepatu Sabut Kelapa Slip-on Shoes (Sumber: Syaifah Mawaddah, 2020)

Tinjauan bentuk yang ditampilkan pada kerajinan sabut kelapa ini yaitu menampilkan bentuk sepatu pria dewasa dengan model Slip-on Shoes, berbahan sabut kelapa yang telah diolah menjadi coco sheet dikombinasikan dengan kain untuk sepatu. Coco sheet digunakan dibagian depan sepatu saja untuk memberikan variasi pada sepatu. Kain berwarna hitam digunakan untuk bagian tepi dan dibagian belakang sepatu, dibagian atas sepatu terdapat karet berwarna putih gunanya agar mudah mengenakan sepatu tersebut dan memang merupakan ciri khas dari slip-on shoes, agar terlihat kontras sol yang digunakan berwarna putih, sepatu ini berukuran $26,5 \mathrm{~cm}$ (nomor 42)
Gorga : Jurnal Seni Rupa

Volume 09 Nomor 01 Januari-Juni 2020

p-ISSN: 2301-5942 | e-ISSN: 2580-2380

Sepatu ini benar terbuat dari sabut kelapa, bukan sabut kelapa yang ditempelkan diatas kerangka sepatu. Proses pembuatan sepatu ini awalnya sabut kelapa diolah menjadi lembaran (coco sheet), setelah itu coco sheet dipotong mengikuti pola bentuk sepatu, lakukan hal yang sama pada pola bagian kain untuk sepatu, lalu coco sheet dan kain di satukan dengan cara dijahit, setelah terbentuk bagian atas sepatu disatukan dengan sol sepatu untuk alasnya dengan cara dilem. Waktu pengerjaan sepatu ini dalam satu bulan pengrajin mampu menghasilkan kurang lebih 100 pasang.

Slip-on Shoes ini adalah periode kedua dalam pembuatan sepatu pada creabrush. Sepatu ini terkesan sederhana namun karena kreativitas sang pengrajin menjadi terlihat unik dan menarik sehingga memiliki nilai jual yang sangat tinggi.

\section{3).Karya 3}

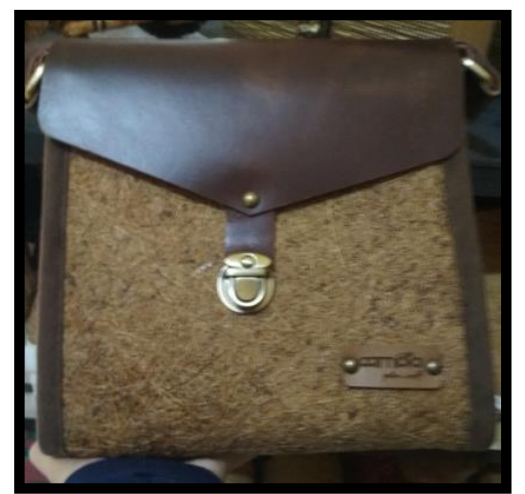

Gambar 3. Tas Selempang Sabut Kelapa (Sumber: Syaifah Mawaddah, 2020)

Tinjauan bentuk yang ditampilkan pada kerajinan sabut kelapa ini yaitu menampilkan bentuk tas selempang dengan bahan sabut kelapa yang telah diolah menjadi coco sheet dikombinasi dengan kulit sintetis, tas ini berbentuk persegi, bagian badan tas dibuat dari coco sheet, sedangkan untuk penutup tasnya dibuat dari kulit sintetis, bagian tepi tas juga dikelilingi kulit sintetis, bagian kancingnya menggunakan kancing tekan yang memberikan kesan mewah pada tas, tali tas berbentuk pipih berjenis webbing polyester berwarna coklat. Tas selempang ini berukuran panjang $18 \mathrm{~cm}$, lebar $7 \mathrm{~cm}$ dan tinggi 21 $\mathrm{cm}$.

Proses pembuatan tas selempang ini menggunakan sabut kelapa yang telah diolah menjadi coco sheet. Coco sheet di potong mengikuti pola bentuk tas, begitu juga untuk kulit sintetis dan kain pelapisnya, kulit sintetis dijahit membentuk tali tas, satukan kulit sintetis dengan coco sheet dengan cara dijahit, satukan 


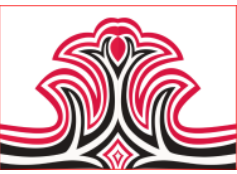

badan tas dengan tali tas yang telah dibuat, beri kain pelapis di dalam tas lalu jahit untuk penyelesaiannya pasang kancing pada bagian depan tas yang telah selesai dibuat.

Tas Selempang ini adalah model kedua pada periode pembuatan tas sabut kelapa. Tas ini sederhana namun karena kreativitas sang pengrajin tas ini terlihat unik, menarik dan terkesan mewah sehingga memiliki nilai jual yang sangat tinggi.

\section{4).Karya 4}

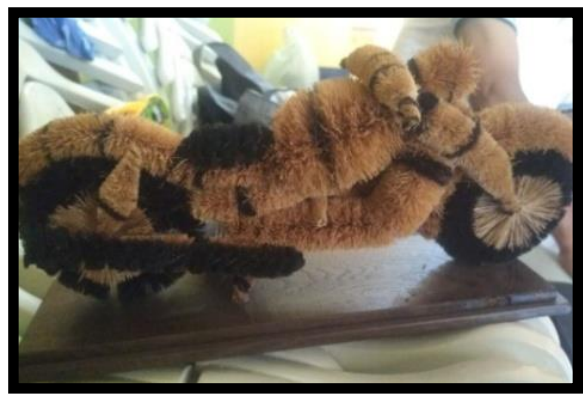

Gambar 4. Miniatur Motor

(Sumber: Syaifah Mawaddah, 2020)

Tinjauan bentuk yang ditampilkan pada kerajinan sabut kelapa ini yaitu menampilkan bentuk miniatur motor dengan bahan sabut kelapa dan ijuk yang dililitkan pada kawat, kerangka bagian-bagian miniatur ini kebanyakan berbentuk silindris yang disesuaikan dengan kerangka motor, seperti pada bagian stang motor yang dibuat mengecil di bagian kanan dan kirinya, pada bagian tangki motor dibuat lebih besar dari bagian yang lain, bagian tempat duduk motor dibuat menggunakan ijuk yang berbentuk oval, pada bagian sayap motor sabut kelapa yang dibengkokkan menjadi setengah lingkaran, sedangkan untuk bannya menggunakan ijuk yang dibuat membentuk lingkaran, pada bagian kenalpot motor juga menggunakan ijuk yang ukurannya lebih kecil dari kerangka motor dan digunakan kayu pipih berdiameter kurang lebih $1,5 \mathrm{~cm}$ sebagai alas dari miniatur motor tersebut. Miniatur ini berukuran panjang $20 \mathrm{~cm}$, lebar $5 \mathrm{~cm}$ dan tinggi $8 \mathrm{~cm}$.

Proses pembuatan miniar ini awalnya sabut kelapa dan ijuk dililitkan ke kawat dengan diameter kurang lebih $5 \mathrm{~cm}$, setelah terlilit bentuk kawat sesuai dengan pola kerangka motor, gunting sabut kelapa dan ijuk membentuk kerangka motor, setelah seluruh kerangka selesai dibuat, satukan setiap bagian kerangka dengan menggunakan lem, lalu rekatkan di atas kayu pipih sebagai alas dan penyangga agar miniatur bisa berdiri dengan tegak.
Gorga : Jurnal Seni Rupa

Volume 09 Nomor 01 Januari-Juni 2020

p-ISSN: 2301-5942 | e-ISSN: 2580-2380

Tidak ada periode dalam pembuatan miniatur ini karena sejak awal pembuatan miniatur ini tidak ada yang berubah. Miniatur ini terkesan sederhana namun karena kreativitas sang pengrajin miniatur ini terlihat unik dan menarik sehingga memiliki nilai jual yang sangat tinggi.

\section{5).Karya 5}

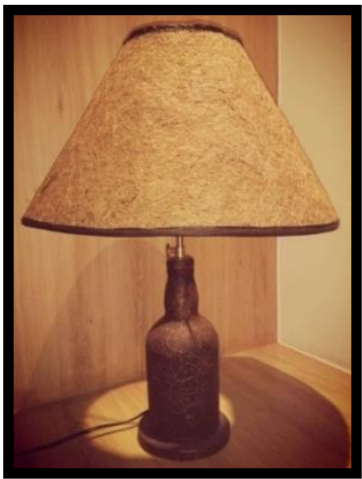

Gambar 4. Cup Lampu Hias (Sumber: @ creabeush_Indonesia, 2019)

Tinjauan bentuk yang ditampilkan pada kerajinan sabut kelapa ini yaitu menampilkan bentuk cup lampu hias dengan bahan sabut kelapa yang telah diolah menjadi coco sheet, pada bagian cup lampu coco sheet dibuat berbentuk kerucut dan bagian tepinya dilapisi dengan kain berwarna coklat, bagian penyangganya berbentuk silindris yang terbuat dari kuningan, sedangkan dudukan lampu berbentuk silindris yang terbuat dari botol bekas dan alasnya terbuat dari kayu yang dibuat melingkar. Untuk cup lampu hiasnya saja berukuran $40 \mathrm{~cm}$.

Proses pembuatan cup lampu hias ini menggunakan sabut kelapa yang telah diolah menjadi coco sheet. Coco sheet di potong mengikuti pola bentuk cup lampu, setelah itu diberi kain pelapis untuk bagian tepinya dengan cara dilem, setelah lem kering jahit bagian coco sheet yang telah diberi kain pelapis agar terlihat rapi, satukan pola bagian cup lampu lem dan jahit kembali. Setelah cup lampu selesai satukan bagian cup lampu dengan badan lampu serta penyangganya.

Tidak ada periode dalam pembuatan kerajinan cup lampu ini karena bentuk cup lampu yang semuanya dominan sama. Cup lampu ini terkesan sederhana namun karena kreativitas sang pengrajin cup lampu ini terlihat unik dan menarik sehingga memiliki nilai jual yang sangat tinggi.

\section{Pembahasan}

Data penelitian karya Creabrush diperoleh dari beberapa sumber, antara lain sumber yang diambil 


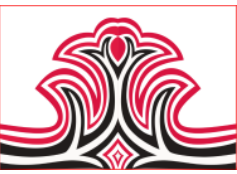

berdasarkan metode observasi, dokumentasi dan wawancara. Semua metode ini memfokuskan pada karya Creabrush secara langsung tentang bahan sabut kelapa, proses pembuatan, bentuk kerajinan, periode pembuatan kerajinan berbahan sabut kelapa, sehingga mendapatkan gambaran yang jelas.

Karya 1 Lukisan sabut kepala menampilkan bentuk wajah perempuan, penyusunan sabut kelapa dan ijuk yang tersusun berdiri. Lukisan berukuran panjang 70 $\mathrm{cm}$, dan lebar $50 \mathrm{~cm}$. Pengerjaan lukisan sabut kelapa memakan waktu kurang lebih dua minggu tergantung tingkat kerumitan gambar dan waktu penjemuran.

Karya 2 menampilkan bentuk sepatu pria dewasa dengan model Slip-on Shoes berukuran $26,5 \mathrm{~cm}$ (nomor 42). Proses pembuatan sepatu ini awalnya sabut kelapa diolah menjadi lembaran (coco sheet), dalam satu bulan pengrajin mampu menghasilkan kurang lebih 100 pasang sepatu.

Karya 3 menampilkan bentuk tas selempang dengan bahan sabut kelapa yang telah diolah menjadi coco sheet dikombinasi dengan kulit sintetis dengan ukuran panjang $18 \mathrm{~cm}$, lebar $7 \mathrm{~cm}$ dan tinggi $21 \mathrm{~cm}$.

Karya 4 menampilkan bentuk miniatur motor dengan bahan sabut kelapa dan ijuk yang dililitkan pada kawat, Miniatur berukuran panjang $20 \mathrm{~cm}$, lebar $5 \mathrm{~cm}$ dan tinggi $8 \mathrm{~cm}$. Tidak ada periode dalam pembuatan miniatur karena sejak awal pembuatannya tidak ada yang berubah.

Karya 5 menampilkan bentuk cup lampu hias dengan bahan sabut kelapa yang telah diolah menjadi coco sheet, berukuran $40 \mathrm{~cm}$. Tidak ada periode dalam pembuatan kerajinan cup lampu karena bentuk cup lampu yang semuanya dominan sama.

\section{KESIMPULAN DAN SARAN}

\section{Kesimpulan}

Berdasarkan hasil tinjauan pada karya diatas, dapat ditarik kesimpulan yaitu Proses pembuatan setiap kerajinan sabut kelapa pada Creabrush memiliki proses pembuatan yang berbeda-beda tergantung dari jenis kerajinannya. Kerajinan sabut kelapa yang ditampilkan Creabrush dibagi menjadi dua kategori berdasarkan fungsinya yaitu kategori homedecor yaitu seperti lukisan, miniature serta cup lampu hias, dan fashioncraft yaitu seperti tas serta sepatu.

\section{Saran}

Berdasarkan hasil penelitian yang sudah dilakukan sebelumnya, maka peneliti menyampaikan beberapa saran yang membangun yaitu : kepada Creabrush semoga dapat menciptakan bentuk-bentuk baru dalam
Gorga : Jurnal Seni Rupa

Volume 09 Nomor 01 Januari-Juni 2020

p-ISSN: 2301-5942 | e-ISSN: 2580-2380

karyanya, kepada Creabrush untuk tetap memelihara, melestarikan, menggalakkan serta mengembangkan industri rumahan yang memanfaatkan bermacam bahan-bahan serat alam yang ada disekitar untuk dijadikan sebuah produk yang bernilai jual tinggi, pemanfaatan sumber daya alam yang sangat melimah diberbagai daerah merupakan aset yang harus dimanfaatkan dengan bijak dan benar, untuk masyarakat umum yang berada disekitar kota Medan dan Deli Serdang untuk lebih melihat lagi produkproduk lokal yang ada disekitar kota medan.

Harapan peneliti hendaknya penelitian ini dilanjutkan dan dikembangkan sehingga dapat memberikan manfaat yang berarti untuk para pelaku industri kreatif khususnya sentra Creabrush.

\section{DAFTAR RUJUKAN}

Depdikbud. (2010). Kamus Praktis Bahasa Indonesia. Jakara : Balai Pustaka.

Ginting, Haris Binar. (2017). Profil Deli Serdang. Deli Serdang: Dinas Komunikasi dan Informatika.

Hartono, Edi Tri. (2013). Mengolah Sabut Kelapa. Yogyakarta: Arcita.

Milasari, dkk. (2018). Seni Budaya. Jakarta: Gramedia.

Milyartiani, Rita, dkk. (2001). Strategi Pembelajaran Kesenian dan Keterampilan. Tangerang Selatan: Universitas Terbuka.

Nurhadiat, Dedy. (2004). Pendidikan Seni Rupa. Jakarta: Grasindo.

Prasetya, Eka Rima. (2016). Pengembangan Modul Prakarya dan Kewirausahaan Materi Kerajinan Berbasis Proses Di SMK. Jurnal Pendidikan Vokasi, 06 (02),154-161.

Ranelis \& Rahmad Washinton, (2016). Rendo Bangku Koto Gadang. Padang Panjang: LPPMPP ISI Padangpanjang. 